\title{
Chitosan-hydroxyapatite composite biomaterials made by a one step co-precipitation method: preparation, characterization and in vivo tests
} \author{
S.N. Lavrynenko, ${ }^{4, *}$ and J.J. Ramsden ${ }^{6}$ \\ ${ }^{1}$ Institute for Applied Physics, National Academy of Sciences of the Ukraine, Sumy, Ukraine \\ ${ }^{2}$ Medical Institute of Sumy State University, Sumy, Ukraine \\ ${ }^{3}$ Sumy State Pedagogical University, Sumy, Ukraine \\ ${ }^{4}$ National Technical University "Kharkov Polytechnic Institute”, Kharkov, Ukraine \\ ${ }^{5}$ National Technical University of Athens, Greece \\ ${ }^{6}$ Cranfield University, Bedfordshire, UK
}

S.N. Danilchenko, ${ }^{1}$ O.V. Kalinkevich, ${ }^{1}$ M.V. Pogorelov, ${ }^{2}$ A.N. Kalinkevich, ${ }^{1}$ A.M. Sklyar, ${ }^{3}$ T.G. Kalinichenko, ${ }^{1}$ V.Y. Ilyashenko, ${ }^{1}$ V.V. Starikov, ${ }^{4}$ V.I. Bumeyster, ${ }^{2}$ V.Z. Sikora,${ }^{2}$ L.F. Sukhodub, ${ }^{1}$ A.G. Mamalis, ${ }^{5}$

\begin{abstract}
A series of biocompatible chitosan/hydroxyapatite composites has been synthesized in an aqueous medium from chitosan solution and soluble precursor salts by a one-step coprecipitation method. The composite materials were produced in dense and porous variants. XRD and IR studies have shown that the apatite crystals in the composites have structural characteristics similar to those of crystals in biogenic apatite. A study of in vivo behaviour of the materials was carried out. Cylindrical rods made of the chitosan/ hydroxyapatite composite material were implanted into the tibial bones of rats. After 5, 10, 15 and 24 days of implantation, histological and histo-morphometric analyses of decalcified specimens were undertaken to evaluate their biocompatibility and the possibility to apply them in bone tissue engineering. The calcified specimens were examined by scanning electron microscopy combined with X-ray microanalysis to compare the elemental composition and morphological characteristics of the implant and the bone during integration. Porous specimens were osteoconducting and were replaced in vivo by newly formed bone tissue.
\end{abstract}

Keywords: biodegradation, chitosan, hydroxyapatite, osteogenesis, scaffolds

\section{INTRODUCTION}

Composites comprising calcium phosphates and natural biopolymers are widely used as biomaterials for bone tissue repair and engineering [1-5]. Hydroxyapatite, $\mathrm{Ca}_{10}\left(\mathrm{PO}_{4}\right)_{6}(\mathrm{OH})_{2}$, has been used as a principal inorganic component of synthetic materials for orthopaedy and stomatology for a long time. This mineral can be regarded, with some limitations, as a crystallochemical analogue of the main mineral constituent of human and animal skeletal tissues [6]. A wide range of biomaterials for different clinical applications can be created on the basis of two components: nanocrystalline apatite and chitosan [3-5, 7-22]. Chitin is the second (after cellulose) most abundant natural polysaccharide. It forms the skeletal system of arthropoda; it is also present in the cell walls of fungi and bacteria. The hardness of the chitin skeletal structures of arthropoda is caused by the formation of natural chitin-calcium carbonate-protein complexes.

Chitosan is a derivative of chitin, obtainable by chitin deacetylation. Chitin and chitosan are polymorphous noncrystalline or partly crystalline biopolymers. Both of them

\footnotetext{
*Corresponding author. E-mail: lavr@kpi.kharkov.ua
}

contain the same monomers, $\mathrm{N}$-acetyl-2-amino-2-deoxyD-glucopyranose and 2-amino-2-deoxy-D-glucopyranose, differing in the relative content of acetylated and deacetylated monomers. Chitin and chitosan are promising materials for medical applications due to their bacteriostatic/bactericidal properties, biocompatibility with human tissues, and the ability to facilitate regenerative processes in healing wounds [17]. In recent years interest in chitosan-hydroxyapatite composite biomaterials has increased significantly, evidenced by the significant growth in the number of scientific articles reporting their characterization and testing.

Several schemes of such composite material production have been developed. Most of them involve two major stages: first, synthesis of the organic polymeric scaffolds of pure or chemically treated and modified chitosan; and second, mineralization of the scaffold in the simulated body fluid (the biomimetic way) or in saturated matrix solutions [7-20]. The scaffolds can be made in the form of membranes, microspheres [27] or multilayered materials. The chitosan can be combined with other macromolecules, such as silk fibroin or carboxymethylcellulose 
$[11,14]$; chitin can also be used as a scaffold [13, 22]. An inverse approach has also been described, viz., preformation of a porous hydroxyapatite scaffold followed by its impregnation with chitosan [8].

The composites obtained in such ways were characterized by different physicochemical methods to test their potential as biomaterials, and also the series of biocompatibility tests using cell cultures were performed, confirming biocompatibility of these composites [8-14]. Yamaguchi et al. [3] have described a one-step scheme of chitosan-hydroxyapatite synthesis, in which the composite was coprecipitated by dropping chitosan solution containing phosphoric acid into a calcium hydroxide suspension. Rusu et al. have developed a stepwise coprecipitation approach [4], using it to obtain different types of chitosan-hydroxyapatite composites with different ratios between the components. These composite materials have been thoroughly characterized by physicochemical techniques and have been found to contain nanosized hydroxyapatite with structural features close to those of biological apatites. A further development of this approach was pursued by Chesnutt et al., who developed microsphere-based chitosan-nanocrystalline calcium phosphate composite scaffolds [26].

A combination of physicochemical and structural characterization of the biomaterials with the results of preclinical in vivo investigations is necessary to find out how changes in the structure and composition of the materials affect their behaviour in living organisms. Since the chitosan-hydroxyapatite materials could be used in bone regeneration as scaffolds in the applications of auto- or allografts, which would otherwise be impossible for some reason or another, the investigation of the processes of biodegradation in vivo is important for further progress in this area, as long as an ideal scaffold material is not yet available. In the present work we tried to synthesize, characterize and evaluate the in vivo behaviour of the simplest (uniform, made by a one-step technique) chitosan-hydroxyapatite materials. It is the first step towards the in vivo investigation of more complicated scaffold systems.

\section{MATERIALS AND METHODS}

\subsection{Materials preparation and characterization}

The examined series of materials had different chitosanapatite concentration ratios. Substances were obtained by adding aqueous solutions of $\mathrm{CaCl}_{2}$ and $\mathrm{NaH}_{2} \mathrm{PO}_{4}$ (keeping the $\mathrm{Ca} / \mathrm{P}$ ratio equal to 1.67 ) to a $0.2 \%$ solution of $75-85 \%$ deacetylated low molecular weight chitosan (Sigma-Aldrich, Brookfield viscosity $=20200 \mathrm{cP}, 1 \%$ in $1 \%$ acetic acid) in $1 \%$ acetic acid. The requisite $\mathrm{pH}$ level was maintained by adding $\mathrm{NaOH}$. The detailed sample preparation varied according to each specimen of a series, as listed in Table 1. The products of the synthesis were aged for $24 \mathrm{~h}$ at room temperature, rinsed thoroughly, and then dried. Water content and chitosanto-apatite ratio were estimated by weighing the sample before and after annealing in air at $130^{\circ} \mathrm{C}$ and $900^{\circ} \mathrm{C}$ for 45 minutes (we assume that the weight loss at $130^{\circ} \mathrm{C}$ corresponds to the water fraction and the weight loss at $900{ }^{\circ} \mathrm{C}$ to the polysaccharide fraction [3]).

To obtain the porous materials, wet (i.e., not dried completely) substances were lyophilized using a laboratory-built glass vacuum system with liquid nitrogen.

Infrared spectra were measured on a Perkin-Elmer Spectrum One spectrometer. Before examination, the powdered samples were mixed with $\mathrm{KBr}$ powder (2.5$3.0 \mathrm{mg}$ of chitosan-apatite composite and $300 \mathrm{mg}$ of $\mathrm{KBr}$ ) and pressed into a solid disk.

The Vickers hardness of the solid samples was measured by the conventional method.

The X-ray diffraction (XRD) crystallographic investigations were performed using DRON4-07 diffractometer ("Burevestnik", Russia). The Ni-filtered $\mathrm{Cu} \mathrm{K}_{\alpha}$ radiation (wavelength $0.154 \mathrm{~nm}$ ) was used with a conventional $\vartheta-2 \vartheta$ Bragg-Brentano geometry ( $2 \vartheta$ is the Bragg angle). The current and voltage of the $\mathrm{X}$-ray tube were $20 \mathrm{~mA}$ and $30 \mathrm{kV}$ respectively. The samples were measured in the continuous registration mode (at a speed of $2 \% \mathrm{~min}$ ) within the $2 \vartheta$-angle range from 8 to $60^{\circ}$. All experimental data processing procedures were performed with the program package DIFWIN-1 ("Etalon PTC" Ltd).

Scanning electron microscopy with X-ray microanalysis was performed using a REMMA102 electron microscope (SELMI, Ukraine). This instrument allows visualization of the sample surface over a wide range of magnifications with a limiting resolution of $c a 10 \mathrm{~nm}$. The characteristic $\mathrm{X}$-ray emission excited by the electron probe (accelerating voltage $20 \mathrm{kV}$, probe current $2 \mathrm{nA}$ ) collected by an energy dispersive X-ray (EDX) detector was used to determine the elemental composition of the sample by scanning over a $50 \times 50 \mu \mathrm{m}^{2}$ area of the surface. To avoid surface charge accumulation the samples were coated with a thin $(30-50 \mathrm{~nm})$ layer of silver in a VUP-5M vacuum device (SELMI, Ukraine).

\subsection{Animal tests}

For the in vivo tests, 48 laboratory rats 4 months old were used, duly observing the requirements of the Ukrainian National Act of Animal Protection against Cruel Treatment (Act №3447-IV 21.02.2006) regulating the care and use of laboratory animals. Perforated defects, 
diameter $2 \mathrm{~mm}$ were made in a sterile operating room with a stomatological borer in the middle third of the right tibia of the animals. The 50/50 chitosan-hydroxyapatite scaffolds were chosen for in vivo evaluation. In the experimental group of animals the cylindrical ChAp rods were implanted into the traumata; the diameter of the rods being equal to the width of the wound channel. The control group consisted of rats with analogous tibial defects not filled with the investigated material. The animals were taken out of the experiment 5, 10, 15 and 24 days after implantation. The phases of removal corresponded to the main stages of reparative osteogenesis [23]. The extracted bones with the defects were fixed in $10 \%$ formalin and then embedded in paraffin in order to prepare histological specimens. Some bones were treated with glutaraldehyde for electron microscopy. The histological and histomorphological analyses of the extracted tissues were performed at the phases of reparative bone regeneration.

\subsection{Characterization of specimens after the in vivo tests}

The elemental composition and morphological characteristics of the tissues were obtained by scanning electron microscopy together with X-ray microanalysis. At the same time, the blood samples were taken from the caudal vein for biochemical analysis. The crude protein in blood plasma was estimated by the Lowry method. The calcium content in blood plasma was examined using a murexide-glycerin reagent. Alkaline phosphatase activity was determined via the decomposition of phenylphosphate with the formation of phenol and consequent reaction of phenol with 4-aminophenazone.

To prepare histological specimens, the defect sites were extracted, fixed in a $10 \%$ solution of neutral formalin, decalcified in EDTA solution over two months, dehydrated in aqueous alcohol solutions with increasing alcohol concentrations, and finally embedded in paraffin. Histological microscopic sections $10-12 \mu \mathrm{m}$ thick were prepared and stained with azure-eosine and by van Giezon's reagent [24]. The microscopic sections were then examined using an Olympus light microscope equipped with a digital camera.

A morphometry study was carried out using the specialized computer programs "VideoTest 5.0" and "VideoSize 5.0" (St. Petersburg, Russia). Five days after the defects were made, the cellular composition of the regenerated tissue was investigated, i.e. the percentage populations of certain cells with respect to the total amount of cells in the site of the defect. The numbers of fibroblasts, macrophages, lymphocytes, plasmocytes, neutrophils, and undifferentiated cells were determined. In the histologic specimens of the next stages of reparative osteogenesis the percentage of granulation tissue, fibroreticular tissue, membrane reticulated and splenial bone tissues, as well as the percentage of the red bone marrow, were determined. The width of bone trabeculae at the periphery and in the central region, and the total area of vessels in the regenerated tissue, were measured.

\section{RESULTS AND DISCUSSION}

The preparation conditions for the series of ChAp composites and the chitosan-to-apatite ratios estimated by simple thermogravimetric analysis are given in Table 1 . The water content was estimated from the weight loss after heating the samples to $130{ }^{\circ} \mathrm{C}$. The total mineral (calcium phosphate) content was measured as the sample weight after complete burnout of the organic moiety at $900{ }^{\circ} \mathrm{C}$. The results from the analyses are in reasonable agreement with the nominal chitosan-toapatite ratios.

Table 1. Sample preparation conditions and chitosan-to-apatite ratios estimated from thermogravimetric measurements.

\begin{tabular}{|c|c|c|c|c|c|c|c|c|}
\hline \multirow{3}{*}{$\begin{array}{c}\text { Sample } \\
\text { No }\end{array}$} & \multicolumn{5}{|c|}{ Ch-Ap preparation } & \multirow{2}{*}{\multicolumn{3}{|c|}{$\begin{array}{c}\text { Thermogravimetric analysis results } \\
\text { wt } \% \text { of components as determined from } \\
\text { weight loss }\end{array}$}} \\
\hline & \multirow{2}{*}{$\begin{array}{l}\mathrm{Ch} / \mathrm{Ap} \\
\text { weight } \\
\text { ratio }\end{array}$} & \multicolumn{2}{|c|}{$\begin{array}{l}\text { chitosan } \\
\text { solution }\end{array}$} & \multicolumn{2}{|c|}{ mineral solution } & & & \\
\hline & & $\begin{array}{c}c \\
\left(w t^{\%} \%\right)\end{array}$ & $V / \mathrm{mL}$ & $\begin{array}{l}1 \mathrm{M} \\
\mathrm{CaCl}_{2} \\
V / \mathrm{mL}\end{array}$ & $\begin{array}{c}1 \mathrm{M} \\
\mathrm{NaH}_{2} \mathrm{PO}_{4} \\
V / \mathrm{mL}\end{array}$ & $\mathrm{H}_{2} \mathrm{O}$ & chitosan & apatite \\
\hline 1 & $\begin{array}{l}\text { ChAp } \\
15 / 85\end{array}$ & 0.2 & 1000 & 113.3 & 68.0 & $9.0 \pm 1.2$ & $14.9 \pm 3.09$ & $76.1 \pm 3.09$ \\
\hline 2 & $\begin{array}{l}\text { ChAp } \\
30 / 70\end{array}$ & 0.2 & 1000 & 46.6 & 28.0 & $11.4 \pm 0.2$ & $25.4 \pm 0.60$ & $63.2 \pm 0.60$ \\
\hline 3 & $\begin{array}{l}\text { ChAp } \\
50 / 50\end{array}$ & 0.2 & 1000 & 20.0 & 12.0 & $3.3 \pm 1.0$ & $49.3 \pm 2.2$ & $47.4 \pm 2.2$ \\
\hline 4 & $\begin{array}{l}\text { ChAp } \\
80 / 20\end{array}$ & 0.2 & 1000 & 5.0 & 3.0 & $8.9 \pm 1.0$ & $73.0 \pm 2.0$ & $18.1 \pm 2.1$ \\
\hline
\end{tabular}


From the IR spectroscopy of the different ChAp composites we can infer that all the major absorbance bands of the spectra correspond to hydroxyapatite; their width increases significantly with increasing chitosan content (Fig. 1). The bands at $1000-1100 \mathrm{~cm}^{-1}$ and 500 $600 \mathrm{~cm}^{-1}$ correspond to different modes of the $\mathrm{PO}_{4}$ group in hydroxyapatite. Broadening of the band at $1050 \mathrm{~cm}^{-1}$ shows the presence of polymer and its interaction with the phosphate groups [20]. The bands at $1420-1485 \mathrm{~cm}^{-1}$ and at about $875 \mathrm{~cm}^{-1}$ are due to the carbonate ions in apatite. The bands at $1550-1700 \mathrm{~cm}^{-1}$ are attributable to mode superposition of the hydroxyapatite $\mathrm{OH}$ group and the chitosan amide I and amide II groups. The bands at $3600-3700 \mathrm{~cm}^{-1}$ and $2800-2950 \mathrm{~cm}^{-1}$ are assigned to the hydroxyl groups present in chitosan [14]. The hydroxyapatite phosphate stretching (vibration) bands are at $1000-1100 \mathrm{~cm}^{-1}$ and the phosphate bending bands are at $500-600 \mathrm{~cm}^{-1}$. The strongest characteristic $\mathrm{CO}_{3}$ bands are also visible, at $1420-1485 \mathrm{~cm}^{-1}$.

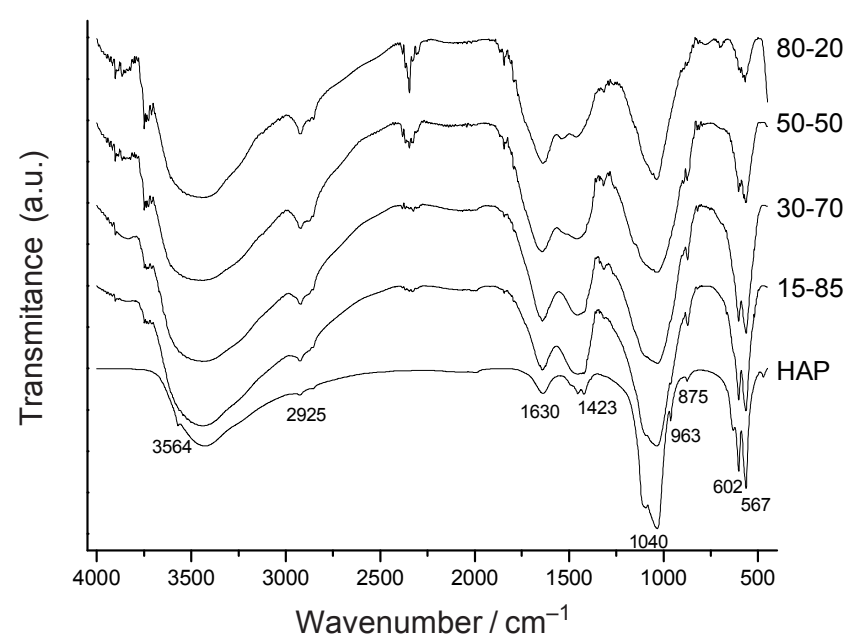

Figure 1. IR spectra of hydroxyapatite and chitosan-hydroxyapatite scaffolds with different chitosan/hydroxyapatite ratios.

XRD patterns suggest the presence of nanocrystalline apatite, its crystallinity decreasing with increasing chitosan content (Fig. 2). Diffraction peak broadening is inversely proportional to crystallite size, hence the greater the proportion of chitosan in the composite the smaller the average size of the apatite crystals. Qualitative estimation of the profile width of the main diffraction peaks suggests that for a chitosan/apatite ratio of 50/50, the size of crystallites in the composite is comparable with the crystallite size of bioapatite in bone tissue $(\sim 20 \mathrm{~nm})$ [25]. Slightly increased intensity of the (002) and (004) peaks compared with the reference data suggests that the apatite crystallites are elongated along the crystallographic axis $\mathbf{A}$ (which is also characteristic of bone tissue bioapatite).

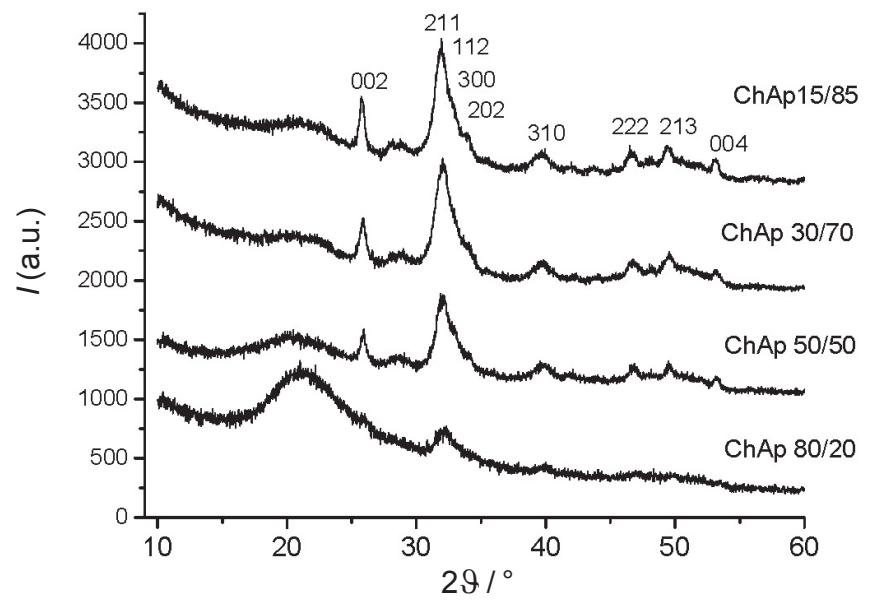

Figure 2. XRD patterns of ChAp samples with different component ratios.

The Vickers hardness of samples with different chitosan-to-apatite ratios amounted to $0.22 \mathrm{GPa}$ for ChAp 15/85; 0.15 GPa for ChAp 30/70; $0.12 \mathrm{GPa}$ for ChAp 50/50; and 0.14 GPa for ChAp 80/20.

$\mathrm{The} \mathrm{Ca} / \mathrm{P}$ ratio determined by EDX microanalysis in the scanning electron microscope was close to that of apatite (1.67). There were no pronounced peaks of $\mathrm{Na}$ and $\mathrm{Cl}$ (Fig. 3), suggesting that the synthesized apatite did not have significant substitutions in the cation $(\mathrm{Na} \rightarrow \mathrm{Ca})$ and anion $(\mathrm{Cl} \rightarrow \mathrm{OH})$ sublattices. Anetwork of micrometre and submicrometre pores was observed in the lyophilized materials. Two systems of pores can be visually distinguished in the micrographs (Fig. 4). The statistical image analysis using the "VideoTest 5.0" and "VideoSize 5.0" programs yielded an average diameter of $30 \mu \mathrm{m}$ for "small" pores and $50 \mu \mathrm{m}$ for "big" ones. Such pores could promote bone tissue growth into the implanted material.

The $\mathrm{Ca}$ and $\mathrm{P}$ contents from the EDX microanalysis of the bones of the model animals after the implantation of solid (nonporous) 50/50 ChAp is shown in Fig. 5. It is clearly seen that the $\mathrm{Ca}$ and $\mathrm{P}$ concentrations in the bone tissue near the defect were restored much faster in the presence of the implanted ChAp than in the control group. It should also be noted that $\mathrm{Ca}$ content does not track $\mathrm{P}$ content for the implant group. This effect may be due to the better mobility and mobilization of Ca compared with $\mathrm{P}$, but the mechanism has not yet been established with certainty.

The implantation of ChAp also reduces calcium mobilization, since the calcium content in blood plasma of the rats with implants was normal, in contrast to the control group of animals. Such reduction of Ca mobilization can prevent the loss of bone strength that usually accompanies the regenerative processes. The total protein content and the alkaline phosphatase activity determined in the blood of the implanted animals did not differ from those of the control group. 


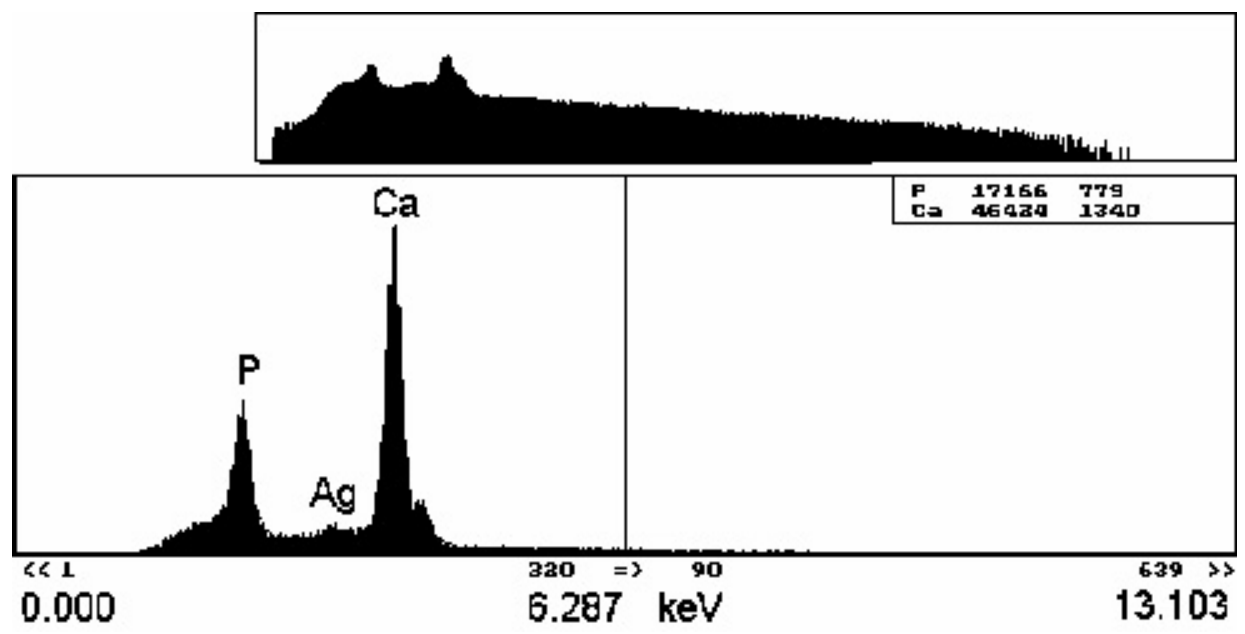

Figure 3. EDX spectrum of the ChAp 50/50 composite. The Ag signal is from the thin conducting Ag film deposited on the samples.
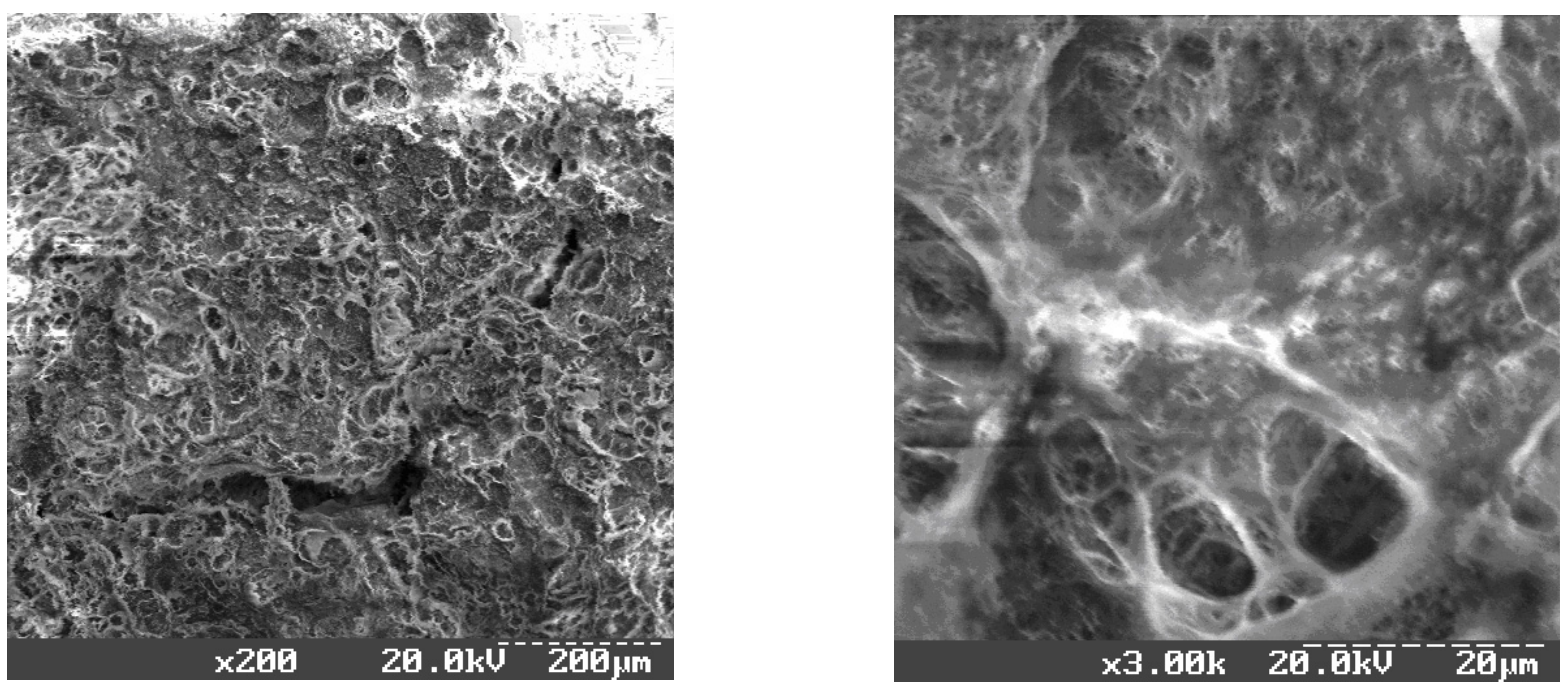

Figure 4. Representative scanning electron micrographs showing the microstructure of the porous ChAp.
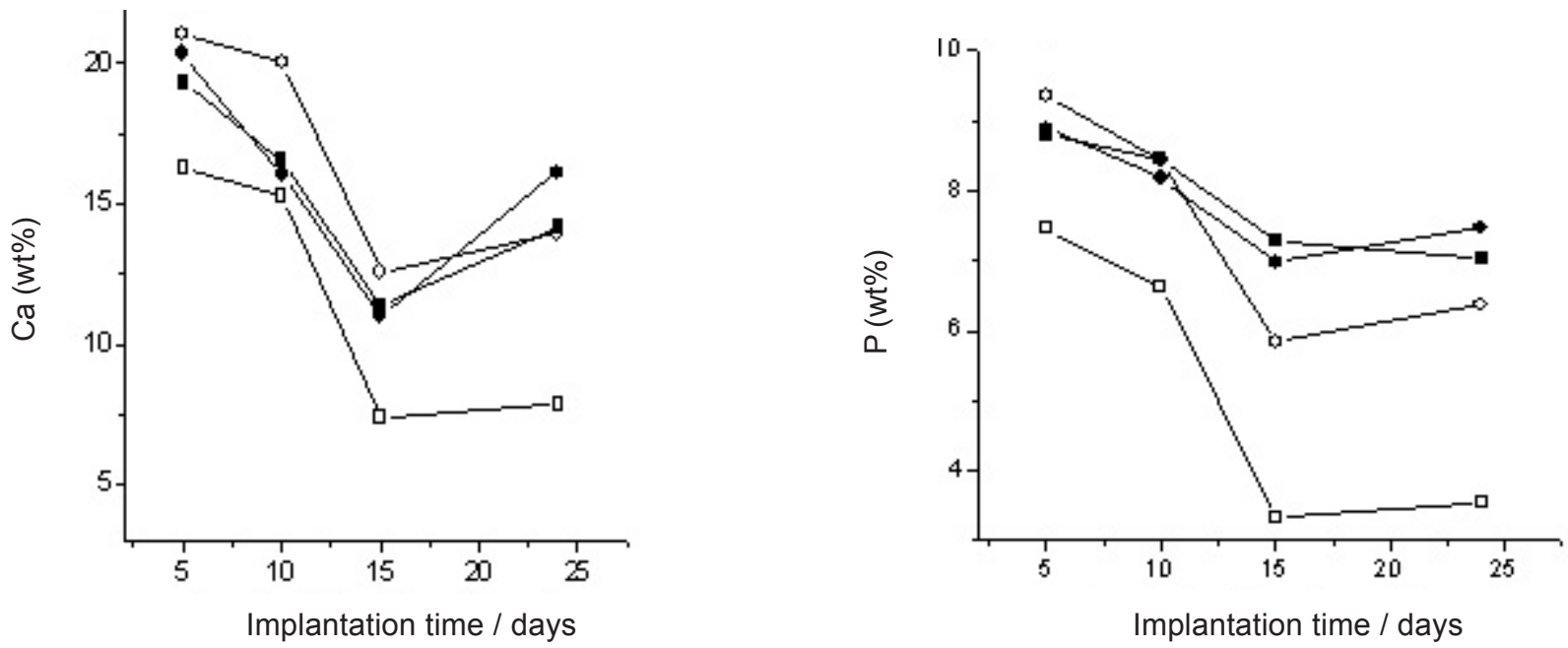

Figure 5. Calcium and phosphorus contents in the bone tissue near the site of implantation (squares) and at the distance of $15 \mathrm{~mm}$ (circles) vs implantation time. Filled symbols: defect with implant; empty symbols: defect without implant (control). 
These data suggest that the nanosized apatite crystals incorporated into the chitosan matrix, being implanted in vivo, participate immediately in the reparative biochemical processes of the living bone tissue. We propose that $\mathrm{Ca}$ and $\mathrm{P}$ from the apatite crystals of the implanted material are used for regenerated bone formation. This reduces the need to mobilize these elements from the bone tissue both in the areas near the defect and those at a distance.

The porous materials have shown osteoconductive properties in the in vivo tests. 5 days after implantation, the pores of ChAp were filled with cells of leukocytemacrophage and fibroblastic differons, providing evidence of progress in the osteoreparative process. Further, the formation of fibroreticular and membrane reticulated primary bone tissue trabeculae occurred with their subsequent calcification and remodelling into the lamellar bone tissue. Starting from the 10th day, the integration of ChAp into the newly formed tissue was observed, and by the 24th day the replacement of the implant by the young bone had taken place. This dynamics is specific only for the porous samples of ChAp. The solid (nonporous) implants did not improve the histological pattern of the reparative process.

The osteoconductive properties of the ChAp composite material can be observed after implantation into the bone defect at the first stages of regenerated bone tissue development. In Fig. 6, pores filled with cell and tissue species typical for regeneration are clearly visible. The young granulation tissue (GT) dominates in the regenerate, its content is $24 \pm 6 \%$. We did not, however, observe a close connexion of tissue components with the material of the implant, which can be explained by the early stage of observations and the high rate of granulation tissue formation. GT occupies the peripheral segments of the defect, which was similar to the patterns observed in the control animals. The central pores of the implant are filled mostly with the cells of posttraumatic haematoma, among which there are macrophages, lymphocytes, fibroblasts, plasmocytes, and undifferentiated cells. The cell percentage corresponded to that of the control group. In one field of view different cell phenotypes were observed: young secreting cells, mature macrophages filled with detritus, and dying cells. In the inner pores the edges of the materials were blurred, which could be indicative of the beginning of ChAp osteointegration and a high activity of cells in this site of the defect. Both in the peripheral and in the central pores vascular invasion was observed, mostly of the sinusoidal type. The vessels were surrounded by a layer of perivascular cells and secreting fibroblasts, the number of which was greater in the peripheral sections.

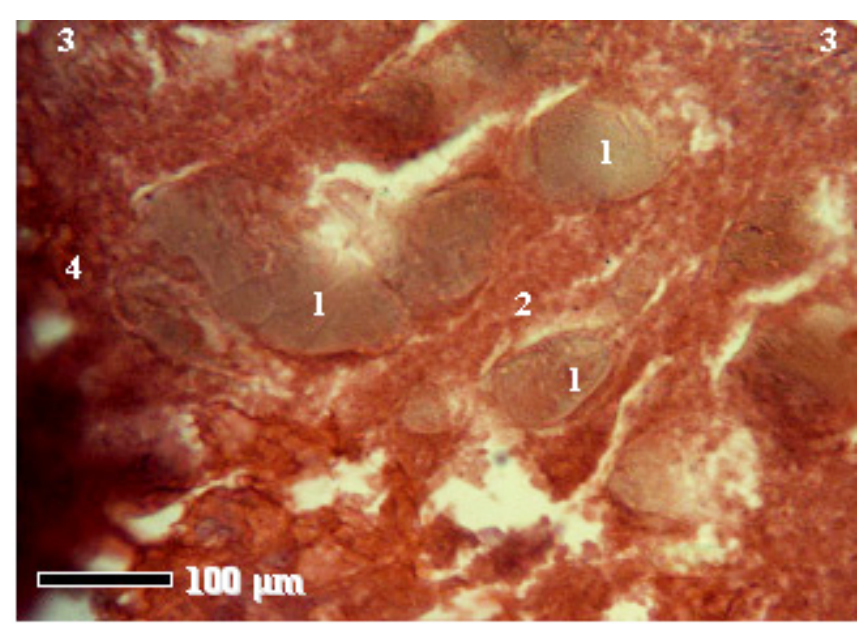

Figure 6. Area of the tibial defect 5 days after traumatization. Key: $1, \mathrm{ChAp} ; 2$, pore with posttraumatic haematoma cells; 3 , granulation tissue; 4 , capillary.

Ten days after the introduction of the implant its rapid biodegradation takes place with the formation of tissuespecific structures of the regenerate. From Fig. 7, the intense growth of fibroreticular tissue (FT) with a more ordered fibre arrangement can be observed in the zone of the defect, and also the beginning of formation of the bone trabeculae formed with the membrane reticulated bone. FT is situated mostly along the periphery of the defect, while its central areas are filled with the remains of granulation tissue with the greatest numbers of fibroblasts, macrophages and sinusoidal capillaries. For the first time the formation of membrane reticulated bone tissue is observed, which can be taken as evidence for the osteoblastic type of reparative processes. The percentage of bone tissue corresponds to that in the control animals ( $35 \pm 10 \%)$, so we cannot comment on the osteoinductive properties of the implant. At the same time, there is integration of the material in the regenerate structure and close binding of the forming bone trabeculae and ChAp.

The histological pattern of the regenerate on the 15th day is similar to that on the 10th day (Fig. 8). Fibroreticular and bone tissues were present, the bone tissue had formed a denser network of trabeculae than in the previous epoch of observation. Granulation tissue was completely absent. The active remodelling of membrane reticulated bone into splenial bone and its mineralization takes place, indicated by the increase of staining intensity of the bone trabeculae. The percentages of FT, membrane reticulated bone and splenial bone were, respectively, $28 \pm 8 \%, 40 \pm 10 \%$ and $11 \pm 3 \%$, the same as in the control series. The remains of the implant are situated mainly in the centre of the defect, closely connected with the bone-forming trabeculae and stained nonuniformly, which suggests their integration into the newly formed bone matrix. 


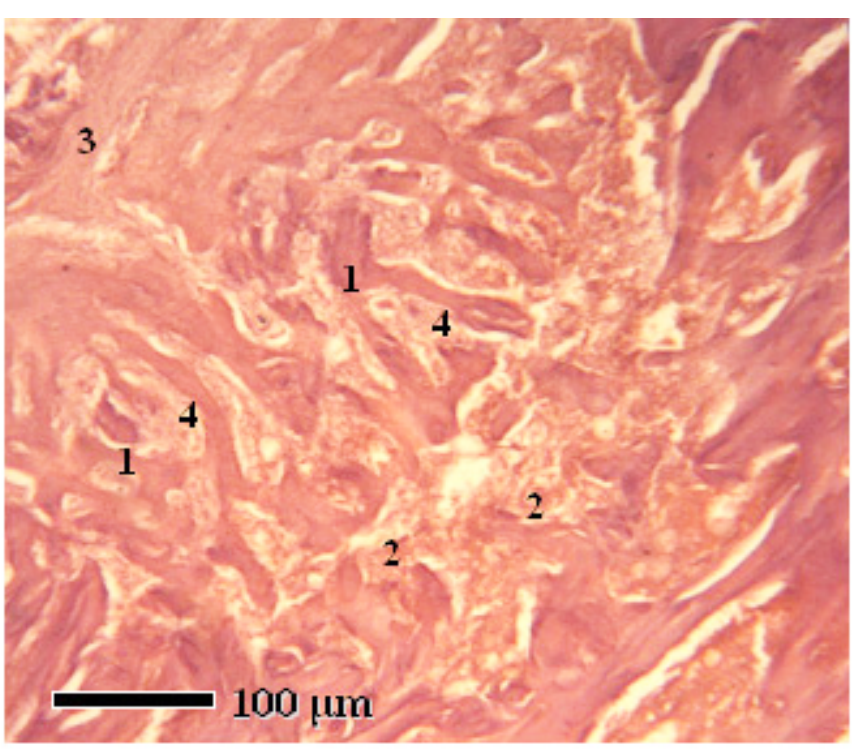

Figure 7. Area of the tibial defect 10 days after traumatization. Key: 1, ChAp; 2, granulation tissue; 3, fibroreticular tissue; 4 , bone trabeculae.

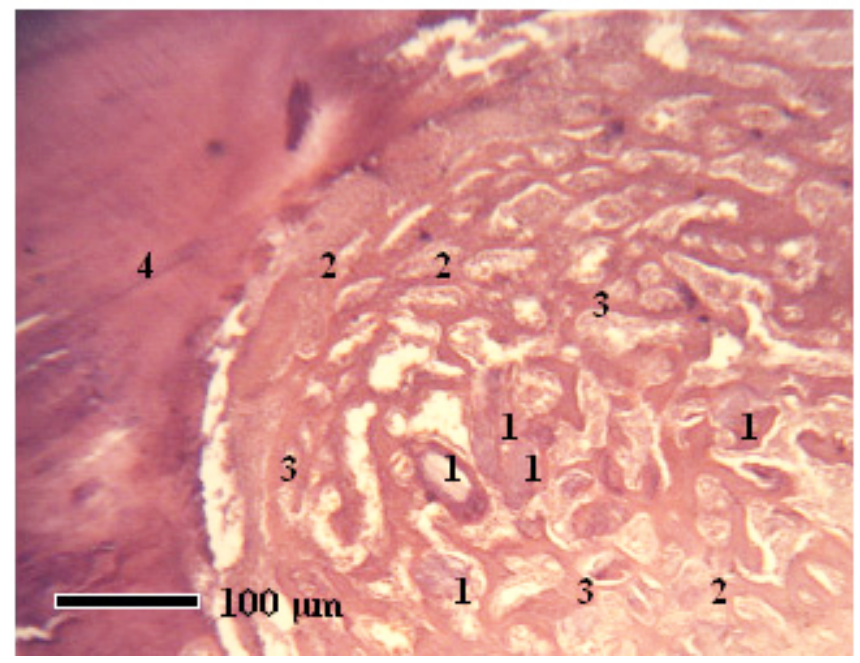

Figure 8. Area of the tibial defect 15 days after traumatization. Key: 1, ChAp; 2, fibroreticular tissue; 3, bone trabeculae; 4, "parent" bone.

On the 24th day of observation, bone tissue occupies the major area of the defect (Fig. 9). The deeper parts of the regenerate are formed with membrane reticulated bone tissue whose stainability is close to that of the "parent" bone. The number of osteoblasts on the surface of trabeculae decreases, which indicates that the intense bone matrix formation process has stopped and the remodelling processes have begun. The remains of nondegraded ChAp are pushed off to the periphery and are on the boundaries with the "parent" bone. Tight bonding of the implant with the newly formed bone matrix is observed; less tight bonding with the "parent" bone. The cortical plate in the site of the defect is formed mostly by splenial bone in which intensive remodelling is observable, as indicated by the presence of both secondary and primary osteons. The number of primary osteons in this observation stage is much greater. So we can well assert that completion of the primary formation of the neogenic bone and the beginning of the remodelling processes has occurred. The implant remains are closely integrated into the newly formed matrix and are subject to biodegradation in the course of bone remodelling.

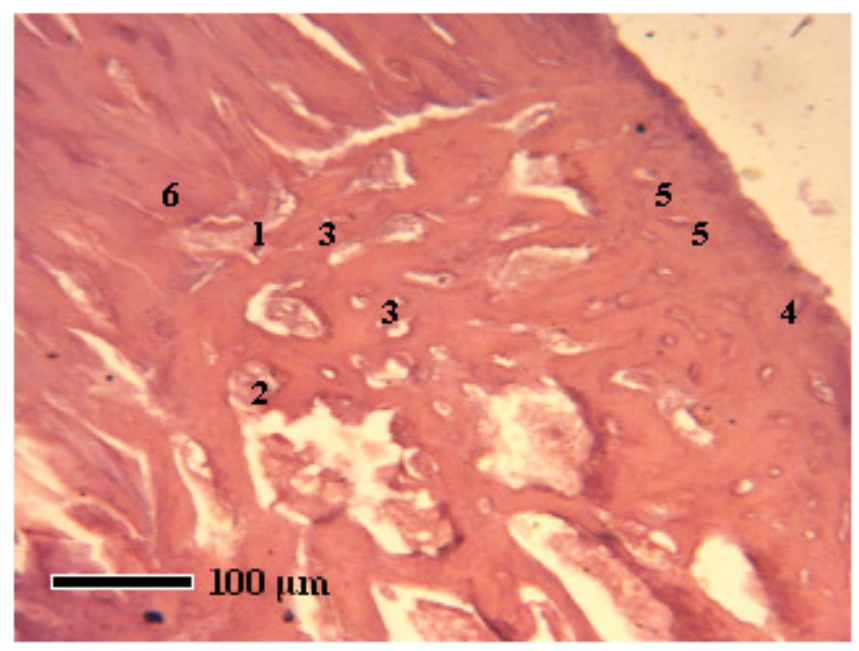

Figure 9. Area of the tibial defect 24 days after traumatization. Key: 1, ChAp; 2, fibroreticular tissue; 3, membrane reticulated bone tissue; 4, splenial bone tissue; 5, osteon; 6, "parent" bone.

\section{CONCLUSIONS}

The investigated chitosan-hydroxyapatite composite materials have proved to be promising for the treatment of bone defects. The results of the present experiments suggest the high potential of simple chitosan-hydroxyapatite composite scaffolds produced by a one-step coprecipitation method as a filling material for orthopaedy and stomatology. The porous chitosan-hydroxyapatite materials have shown good osteoconductive properties in in vivo experiments. Histomorpologiocal studies have shown that the porous materials undergo almost complete biodegradation. The complete replacement of the porous chitosan-hydroxyapatite composite implant by the newly formed bone tissue within the bone defect in rats takes place by the 24 th day of implantation.

\section{REFERENCES}

1. Wahl, D.A. and Czernuszka, J.T. Collagen-hydroxyapatite composites for hard tissue repair. Eur. Cells Mater. 11 (2006) 43-56.

2. Chang, M.C., Ko, C.C. and Douglas, W.H. Preparation of hydroxyapatite-gelatin nanocomposite. Biomaterials 24 (2003) 2853-2862.

3. Yamaguchi, I., Tokuchi, K., Fukuzaki, H., Koyama, Y., 
Takakuda, K., Monma, H. and Tanaka, J. Preparation and microstructure analysis of chitosan/hydroxyapatite nanocomposites. J. Biomed. Mater. Res. 55 (2001) 20-27.

4. Rusu, V.M., Chuen-How, Ng., Wilke, M., Tiersch, B., Fratzl, P. and Peter, M.G. Size-controlled hydroxyapatite nanoparticles as self-organized organic-inorganic composite materials. Biomaterials 26 (2005) 5414-5426.

5. Hu, Q., Li, B., Wang, M. and Shen, J. Preparation and characterization of biodegradable chitosan/hydroxyapatite nanocomposite rods via in situ hybridization: a potential material as internal fixation of bone fracture. Biomaterials 25(2004) 779-785.

6. Elliott, J.C. Calcium phosphate biominerals. In: Phosphates: Geochemical, Geobiological and Materials Importance (eds M.J. Kohn, J. Rakovan and J.M. Hughes ), (vol. 48 of the Reviews in Mineralogy and Geochemistry series), pp. 427-454. Washington, DC: Mineralogical Society of America (2002).

7. Zhang, Y. and Zhang, M.Q. Synthesis and characterization of macro-porous chitosan/calcium phosphate composite scaffolds for tissue engineering. J. Biomed. Mater. Res. 55 (2001) 304-312.

8. Oliveira, J.M., Rodrigues, M.T., Silva, S.S., Malafaya, P.B., Gomes, M.E., Viegas, C.A., Dias, I.R., Azevedo, J.T., Mano, J.F. and Reis, R.L. Novel hydroxyapatite/chitosan bilayered scaffold for osteochondral tissue-engineering applications: scaffold design and its performance when seeded with goat bone marrow stromal cells. Biomaterials 27 (2006) $6123-6137$.

9. Zhao, F., Grayson, W.L., Ma, T., Bunnell, B. and Lu, W.W. Effects of hydroxyapatite in 3-D chitosan-gelatin polymer network on human mesenchymal stem cell construct development. Biomaterials 27 (2006) 1859-1867.

10. Li, J., Chen, Y.P., Yin, Y., Yao, F. and Yao, K. Modulation of nano-hydroxyapatite size via formation on chitosan-gelatin network film in situ. Biomaterials 28 (2007) 781-790.

11. Wang, L. and Li, C. Preparation and physicochemical properties of a novel hydroxyapatite/chitosan-silk fibroin composite. Carbohydrate Polym. 68 (2007) 740-745.

12. Jiang, L.Y., Lia, Y.B., Zhanga, L. and Wang, X.J. Preparation and characterization of a novel composite containing carboxymethyl cellulose used for bone repair. Mater. Sci. Engng C 29 (2009) 193-198.

13. Madhumathi, K., Binulal, N.S., Nagahama, H., Tamura, H., Shalumon, K.T., Selvamurugan, N., Nair, S.V. and Jayakumar, R. Preparation and characterization of novel $\beta$-chitinhydroxyapatite composite membranes for tissue engineering applications. Int. J. Biol. Macromol. 44 (2009) 1-5.

14. Jiang, L., Li, Y., Wang, X., Zhang, L., Wen, J. and Gong, M. Preparation and properties of nano-hydroxyapatite/ chitosan/carboxymethyl cellulose composite scaffold. Carbohydrate Polym. 74 (2008) 680-684.
15. Li, J., Dou, Y., Yang, J., Yin, Y., Zhang, H., Yao, F., Wang, V. and Yao, K. Surface characterization and biocompatibility of micro- and nano-hydroxyapatite/chitosan-gelatin network films. Mater. Sci. Engng C 29 (2008) 1207-1215.

16. Aimoli, C.G. and Beppu, M.M. Precipitation of calcium phosphate and calcium carbonate induced over chitosan membranes: a quick method to evaluate the influence of polymeric matrices in heterogeneous calcification. Colloids Surf. B 53 (2006) 15-22.

17. Muzzarelli, R.A.A. Chitins and chitosans for the repair of wounded skin, nerve, cartilage and bone. Carbohydrate Polym. 76(2009) 167-182.

18. Kong, L., Gao, Y., Lu, G., Gong, Y., Zhao, N. and Zhang, X. A study on the bioactivity of chitosan/nano-hydroxyapatite composite scaffolds for bone tissue engineering. Eur. Polym. J. 42 (2006) 3171-3179.

19. Leonor, I.B., Baran, E.T., Kawashita, M., Reis, R.L., Kokubo, T. and Nakamura, T. Growth of a bone-like apatite on chitosan microparticles after a calcium silicate treatment. Acta Biomaterialia 4 (2008) 1349-1359.

20. Manjubala, I., Scheler, S., Bossert, J. and Jandt, K.D. Mineralisation of chitosan scaffolds with nano-apatite formation by double diffusion technique. Acta Biomaterialia 2 (2006) 75-84.

21. Ito, M. In vitro properties of a chitosan-bonded hydroxyapatite bone-filling paste. Biomaterials 12 (1991) 41-45.

22. Ge, Z., Baguenard, S., Lim, L.Y. et al. Hydroxyapatite-chitin materials as potential tissue engineered bone substitutes. Biomaterials 25 (2004) 1049-1058.

23. Korzh, N.A. and Dedukh, N.V. Reparative regeneration of bone: modern view of the problem. Regeneration stages. Ortopedia, travmatologia i protezirovanie 1 (2006) 77-83.

24. Wheater, P.R., Burkitt, H.G. and Daniels, V.G. Functional Histology, 2nd edn. Edinburgh: Churchill-Livingstone (1987).

25. Danilchenko, S.N., Kukharenko, O.G., Moseke, C. et al. Determination of the bone mineral crystallite size and lattice strain from diffraction line broadening. Cryst. Res. Technol. 37 (2002) 1234-1240.

26. Chesnutt, B.M., Viano, A.M., Yuan, Y., Yang, Y., Guda, T., Appleford, M.R., Ong, J.L., Haggard, W.O. and Bumgardner, J.D. Design and characterization of a novel chitosan/nanocrystalline calcium phosphate composite scaffold for bone regeneration. J. Biomed. Mater. Res. A 88 (2009) 491-502.

27. Abdel-Fattah, W.I., Jiang, T., El-Tabie El-Bassyouni, G. and Laurencin, C.T. Synthesis, characterization of chitosans and fabrication of sintered chitosan microsphere matrices for bone tissue engineering. Acta Biomaterialia 3 (2007) 503-514. 